\title{
Battery Charging Station for Electric Vehicles based on Bipolar dc Power Grid with Grid-to-Vehicle, Vehicle-to-Grid and Vehicle-to-Vehicle Operation Modes
}

\author{
Tiago J. C. Sousa ${ }^{1}$, Vítor Monteiro ${ }^{1}$, Sérgio Coelho ${ }^{1}$, Luís Machado ${ }^{1}$, Delfim Pedrosa ${ }^{1}$, \\ João L. Afonso ${ }^{1}$ \\ ${ }^{1}$ Centro ALGORITMI, University of Minho, Campus de Azurém, Guimarães, Portugal \\ tsousa@dei.uminho.pt
}

\begin{abstract}
This paper proposes an electric vehicle (EV) battery charging station (EV-BCS) based on a bipolar dc power grid with the capabilities of returning energy back to the power grid (vehicle-to-grid - V2G mode), as well as to perform power transfer between different EVs connected to the EV-BCS without drawing power from the power grid (vehicle-to-vehicle $-\mathrm{V} 2 \mathrm{~V}$ mode), besides the traditional battery charging operation (grid-to-vehicle - G2V mode). The proposed EV-BCS is modular, using three-level bidirectional dc-dc converters. In this paper, for simplicity reasons, only two converters, and hence two EVs, are considered in order to validate the previously referred operation modes. Furthermore, unbalanced operation from the EVs side is also considered for all the operation modes, aiming to consider a real scenario of operation. Simulation results verify the correct operation of the EV-BCS in all cases, with balanced and unbalanced current consumption from the EVs resulting always in balanced currents from the bipolar dc power grid side.
\end{abstract}

Keywords: Electric Vehicle, Battery Charging Station, Bipolar dc Power Grid, Three-Level dc-dc Converter.

\section{Introduction}

It is well-known that electric vehicles (EVs) are a promising alternative to the conventional vehicles based on internal combustion engines regarding the emission lessening of greenhouse gasses at the user level, as well as the reduction in the exploitation of fossil resources [1], [2]. Furthermore, in addition to the aforementioned advantages in terms of mobility, EVs are also a promising solution concerning smart grids, being able to render ancillary services in conjunction with renewable energy sources and energy storage systems [3]-[5]. Besides the traditional battery charging operation, i.e. grid-to-vehicle $(\mathrm{G} 2 \mathrm{~V})$ operation mode, one of the first operation modes proposed in the literature regarding the connection of EVs to the power grid was the vehicle-to-grid (V2G) [6], [7], consisting of using part of the energy stored in the EV battery to deliver it to the power grid. Other operation modes for the EV in the context of smart grids can 
be analyzed in [8]. However, to make EVs ascend to a global level, a suitable infrastructure in terms of battery charging is mandatory. In this sense, several scheduling strategies regarding EV battery charging stations (EV-BCSs) have been proposed in the literature [9]-[12], as well as battery swapping strategies [13]-[16] and the combination with energy storage systems and solar photovoltaic panels [17]-[19].

In addition to EVs, dc power grids have also been gaining attention, mainly due to the fact that energy storage systems and solar photovoltaic panels, which are major assets towards distributed generation and, consequently, smart grids and microgrids, operate in dc. Moreover, dc power systems are more efficient than their ac counterparts, not suffering from skin effect, and not presenting electrical issues such as reactive power and harmonic currents. In this sense, dc microgrids have been an important topic of research [20], [21]. Among dc power grids can be found unipolar or bipolar types, whether they are comprised by one active conductor plus neutral or two active conductors plus neutral, respectively. As suggested by their designation, bipolar dc power grids provide two symmetrical voltages referenced to the same potential, i.e., the neutral wire. Additionally, it is possible to obtain a voltage that is the double of the base value, namely by using the negative rail as reference instead of the neutral wire. This is advantageous in the way that allows to have two different voltage values instead of only one, as happens with unipolar dc power grids. Besides, bipolar dc power grids are more reliable and present a higher energy transmission capacity [22]-[24].

The application of bipolar dc power grids in EV-BCSs has been already addressed in the literature. In [25] is presented an EV-BCS based on a neutral point clamped front-end ac-dc converter, whose split dc-link generates a bipolar dc power grid, where the dc-dc converters responsible for the battery charging operation are connected. However, only the front-end ac-dc converter is addressed in such work. In [26]-[29] is studied the utilization of three-level dc-dc converters in an EV-BCS based on a bipolar dc power grid, but the V2G operation mode is not addressed. In this context, this paper presents an EV-BCS based on a bipolar dc power grid with G2V and V2G capability. Besides, the vehicle-to-vehicle (V2V) operation mode is also taken into consideration, which is a relatively recent operation mode regarding EVs but being already a relevant research topic [30]-[33]. It should be noted that the front-end ac-dc converter of the EV-BCS is not addressed in this paper.

The rest of the paper is structured as follows: Section 2 presents the structure of the EV-BCS, as well as the control of the power converters; Section 3 presents the simulation model and results of the EV-BCS in the different possible operation modes; finally, Section 4 finalizes the paper with the main conclusions.

\section{Structure of the Electric Vehicle Battery Charging Station}

This section describes the power structure of the proposed EV-BCS, namely the dc-dc converter used and its control system. The chosen topology for the dc-dc converter is the three-level two-quadrant buck-boost, since it is bidirectional, allowing bidirectional power flow and, hence, the G2V and V2G operation modes, among others, and also because it has a split dc-link in its high voltage side, making it suitable for bipolar $\mathrm{dc}$ 
power grids [34], [35]. Fig. 1 shows the power structure of the EV-BCS, where two three-level two-quadrant buck-boost dc-dc converters can be seen, both sharing the same dc-link, which is connected to a bipolar dc power grid. The figure suggests the modularity of the EV-BCS, being possible to connect an indefinite number of similar dc-dc converters to the bipolar dc power grid. For the sake of simplicity, the analysis carried out in this paper only comprises two dc-dc converters, consequently representing two EVs. In [36] a study of the same power structure can be found, i.e., two three-level two-quadrant buck-boost dc-dc converters connected to each other by the high voltage side, focusing on smart grid applications.

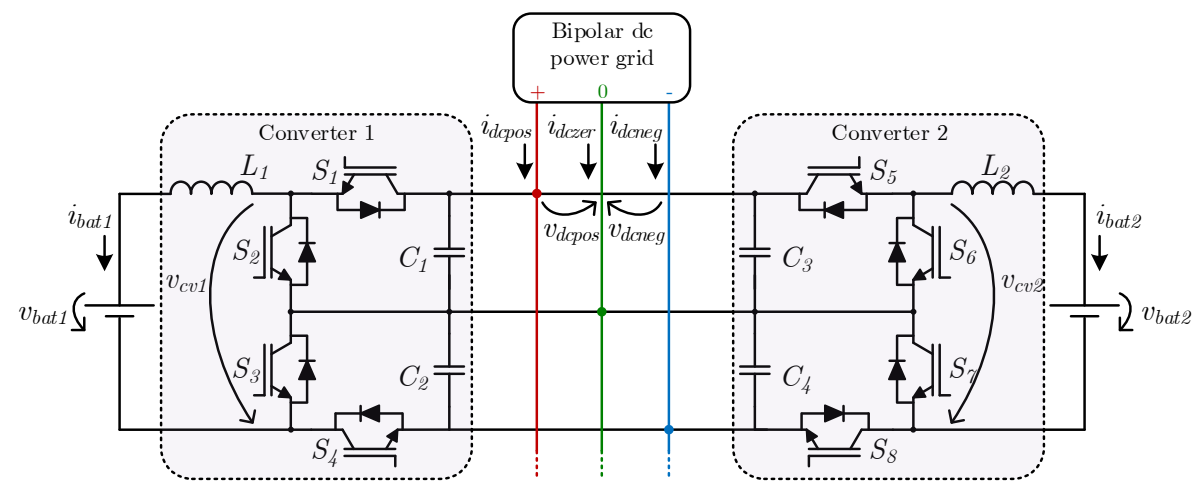

Fig. 1. Power structure of the proposed EV-BCS.

Each converter $x$ (with $x$ varying from 1 to the total number of converters, in this case being 2) is connected to an EV $x$ in the low voltage side, with $v_{\text {batx }}$ and $i_{\text {batx }}$ being its battery voltage and current, respectively, and to the bipolar dc power grid in the high voltage side, with the positive rail voltage $\left(v_{d c p o s}\right)$ being applied to the upper capacitor $\left(C_{2 x-1}\right)$ and the negative rail voltage $\left(v_{d c n e g}\right)$ being inversely applied to the lower capacitor $\left(C_{2 x}\right)$. In a bipolar dc power grid, the condition $v_{d c p o s}=-v_{d c n e g}$ is verified; therefore, the total voltage in the high voltage side of each converter $x$, i.e., across the series connection of the capacitors $C_{2 x-1}$ and $C_{2 x}$, is $2 v_{d c p o s}$. However, due to the three-level characteristic of the converter, each power semiconductor withstands only a maximum voltage of $v_{\text {dcpos. }}$.

For the proper operation of each converter $x$ in buck mode, the power semiconductors $S_{4 x-3}$ and $S_{4 x}$ are used ( $S_{1}$ and $S_{4}$ for converter 1 and $S_{5}$ and $S_{8}$ for converter 2 ). In this operation mode, the power flows from the high voltage side to the low voltage side, i.e., from the dc power grid to the battery, corresponding to the $\mathrm{G} 2 \mathrm{~V}$ operation mode. The voltage produced by each converter $x\left(v_{c v x}\right)$ can assume three values, namely 0 , $v_{d c p o s}$ and $2 v_{d c p o s}$. Equation (1) shows the possible values of the voltage $v_{c v x}$ as a function of the switching state of the power semiconductors in buck mode, with 0 meaning the off state and 1 meaning the on state, and equation (2) shows the two possible operating regions for the converter in function of the voltages $v_{\text {batx }}$ and $v_{d c p o s}$ and the duty-cycle (D). It should be noted that the switching signals of the two power semiconductors must 
be $180^{\circ}$ phase shifted in order to assure the proper operation of the converter, also doubling the frequency of the voltage produced by the converter with respect to its switching frequency.

$$
\begin{aligned}
& v_{c v x}=\left\{\begin{aligned}
0, & S_{4 x-3}=0, S_{4 x}=0 \\
v_{\text {dcpos }}, & S_{4 x-3}=0(1), S_{4 x}=1(0) . \\
2 v_{\text {dcpos }}, & S_{4 x-3}=1, S_{4 x}=1
\end{aligned}\right. \\
& \text { If } v_{c v x}<2 v_{d c p o s}-v_{\text {batx }} \rightarrow D<50 \%, v_{c v x}=\left\{0, v_{d c p o s}\right\}, \\
& \text { If } v_{c v x}>2 v_{\text {dcpos }}-v_{\text {batx }} \rightarrow D>50 \%, v_{c v x}=\left\{v_{\text {dcpos }}, 2 v_{\text {dcpos }}\right\} \text {. }
\end{aligned}
$$

In order to control each EV battery current, a predictive control strategy was employed, based on the model of the converter. Hence, the voltage that each converter $x$ must produce $\left(v_{c v x}\right)$ in a given instant $k$ in order to control the EV battery current $i_{\text {batx }}$ according to its reference $\left(i_{\text {batrefx }}\right)$ in buck mode obeys the following digital implementation:

$$
v_{c v x}[k]=v_{\text {batx }}[k]+L_{x} f_{s}\left(i_{\text {batrefx }}[k]-i_{\text {batx }}[k]\right), \quad i_{\text {bat }}>0,
$$

where $L_{x}$ is the inductance value of dc-dc converter $x$ inductor and $f_{s}$ is the sampling frequency used in the digital control system.

For the proper operation of each converter $x$ in boost mode, the power semiconductors $S_{4 x-2}$ and $S_{4 x-1}$ are used ( $S_{2}$ and $S_{3}$ for converter 1 and $S_{6}$ and $S_{7}$ for converter 2 ). In this operation mode, the power flows from the low voltage side to the high voltage side, i.e., from the battery to the dc power grid, corresponding to the V2G operation mode. The voltage produced by each converter $x\left(v_{c v x}\right)$ can assume three values, namely 0 , $v_{d c p o s}$ and $2 v_{d c p o s}$. Equation (4) shows the possible values of the voltage $v_{c v x}$ as a function of the switching state of the power semiconductors in boost mode, with 0 meaning the off state and 1 meaning the on state, and equation (5) shows the two possible operating regions for the converter in function of the voltages $v_{\text {batx }}$ and $v_{d c p o s}$ and the duty-cycle (D). Similarly to the buck mode, the switching signals of the two power semiconductors must be $180^{\circ}$ phase shifted in order to assure the proper operation of the converter, also doubling the frequency of the voltage produced by the converter with respect to its switching frequency.

$$
\begin{aligned}
& v_{c v x}=\left\{\begin{aligned}
0, & S_{4 x-2}=1, S_{4 x-1}=1 \\
v_{d c p o s}, & S_{4 x-2}=1(0), S_{4 x-1}=0(1) . \\
2 v_{d c p o s}, & S_{4 x-2}=0, S_{4 x-1}=0
\end{aligned}\right. \\
& \text { If } v_{c v x}>2 v_{d c p o s}-v_{\text {batx }} \rightarrow D>50 \%, v_{c v x}=\left\{0, v_{d c p o s}\right\}, \\
& \text { If } v_{c v x}<2 v_{d c p o s}-v_{\text {batx }} \rightarrow D<50 \%, v_{c v x}=\left\{v_{d c p o s}, 2 v_{d c p o s}\right\} .
\end{aligned}
$$

In order to control each battery current, a predictive control strategy was employed, based on the model of the converter. Hence, the voltage that each converter $x$ must 
produce $\left(v_{c v x}\right)$ in a given instant $k$ in order to control the battery current $i_{\text {batx }}$ according to its reference $\left(i_{\text {batref } x}\right)$ in boost mode obeys the following digital implementation:

$$
v_{c v x}[k]=v_{\text {batx }}[k]-L_{x} f_{s}\left(i_{\text {batx }}[k]-i_{\text {batrefx }}[k]\right), \quad i_{\text {bat }}<0,
$$

where $L_{x}$ is the inductance value of dc-dc converter $x$ inductor and $f_{s}$ is the sampling frequency used in the digital control system.

\section{Computational Simulations}

This section presents the simulation parameters and results of the EV-BCS for two EVs, being addressed the $\mathrm{G} 2 \mathrm{~V}, \mathrm{~V} 2 \mathrm{G}$ and $\mathrm{V} 2 \mathrm{~V}$ operation modes, as well as a combination of $\mathrm{V} 2 \mathrm{~V}$ with $\mathrm{G} 2 \mathrm{~V}$ and V2V with V2G. The simulations were carried out in the software PSIM v9.1 from Powersim. In Fig. 2 it can be seen the used battery model, namely the Thevenin model, comprised by the open-circuit voltage $\left(v_{o c x}\right)$, a capacitor to emulate the dynamic behavior of the battery $\left(C_{b a t x}\right)$, a resistor connected in parallel with the capacitor to emulate the battery self-discharge $\left(R_{p x}\right)$ and a series resistor, meaning the internal resistance of the battery $\left(R_{s x}\right)$. Table 1 presents the parameters of the power converter and batteries of each EV (where it can be seen that the converters are equal), as well as the batteries, which present different initial voltage values, with $v_{\text {batl }}$ starting with $250 \mathrm{~V}$ and $v_{\text {bat } 2}$ with $200 \mathrm{~V}$.

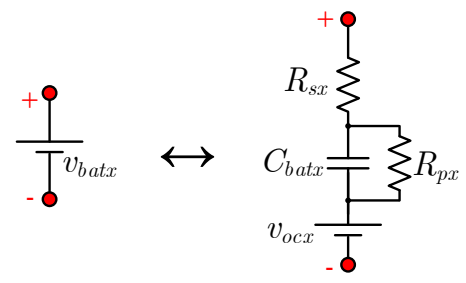

Fig. 2. Battery model used for each $\operatorname{EV} x$.

Table 1. Simulation parameters of the EV-BCS and EV batteries.

\begin{tabular}{cc}
\hline \hline PARAMETER & VALUE \\
\hline \hline Initial $v_{\text {batl }}$ & $250 \mathrm{~V}$ \\
\hline Initial $v_{\text {bat } 2}$ & $200 \mathrm{~V}$ \\
\hline$v_{\text {ocx }}$ & $150 \mathrm{~V}$ \\
\hline$C_{\text {batx }}$ & $0.5 \mathrm{~F}$ \\
\hline$R_{s x}$ & $0.1 \Omega$ \\
\hline$R_{p x}$ & $100 \mathrm{k} \Omega$ \\
\hline$L_{x}$ & $500 \mu \mathrm{H}$ \\
\hline$C_{2 x-1}, C_{2 x}$ & $100 \mu \mathrm{F}$ \\
\hline$v_{d c p o s}$ & $200 \mathrm{~V}$ \\
\hline$v_{d c n e g}$ & $-200 \mathrm{~V}$ \\
\hline dc power grid impedance & $0.1 \Omega, 10 \mu \mathrm{H}$ \\
\hline Switching frequency & $50 \mathrm{kHz}$ \\
\hline Sampling frequency & $50 \mathrm{kHz}$ \\
\hline
\end{tabular}


Fig. 3 shows the normal operation of both EVs at a charging station, i.e., both operating in $\mathrm{G} 2 \mathrm{~V}$, and both charging their batteries with the same value of current $(20 \mathrm{~A})$. The figure shows the battery voltages $\left(v_{\text {bat } 1}\right.$ and $\left.v_{\text {bat } 2}\right)$ and currents $\left(i_{\text {batl }}\right.$ and $\left.i_{\text {bat } 2}\right)$, the currents drawn from the dc power grid, namely in the positive rail $\left(i_{d c p o s}\right)$, neutral rail $\left(i_{d c z e r}\right)$ and negative rail $\left(i_{d c n e g}\right)$, and the voltages produced by the converters $\left(v_{c v l}\right.$ and $\left.v_{c v 2}\right)$. It can be seen that the battery voltages are slightly higher than their original values $(2 \mathrm{~V}$ higher), which is due to the internal resistance of the batteries and not due to the energy accumulation process, given that the initial instant of figure is $2 \mathrm{~ms}$. It can be seen that both battery currents present the same average value of $20 \mathrm{~A}$, but $i_{\text {bat } 2}$ presents a much smaller ripple than $i_{\text {batl }}$. This is due to the fact that the voltage $v_{\text {bat } 2}$ is practically half $(202 \mathrm{~V})$ the total dc power grid voltage, which makes the three-level buck-boost dc-dc converter operate in a region of strong ripple cancelling. This is visible in the voltage produced by this converter $\left(v_{c v 2}\right)$, presenting a very low duty-cycle between voltage levels $200 \mathrm{~V}$ and $400 \mathrm{~V}$ (in other words, presenting a duty-cycle slightly higher than $50 \%$ ). It is noticeable from the voltage $v_{c v l}$ that converter 1 operates with the same voltage levels but with a higher duty-cycle, meaning a higher ripple in $i_{\text {bat }}$. Regarding the currents absorbed from the dc power grid, it can be perceived that $i_{d c p o s}$ and $i_{\text {dcneg }}$ are symmetrical, with average values of $23 \mathrm{~A}$ and $-23 \mathrm{~A}$, respectively, the first one being positive and the second being negative, meaning that the dc power grid is providing power. The current $i_{d c z e r}$ is the negative sum of $i_{d c p o s}$ and $i_{d c n e g}$, therefore presenting a null average value.

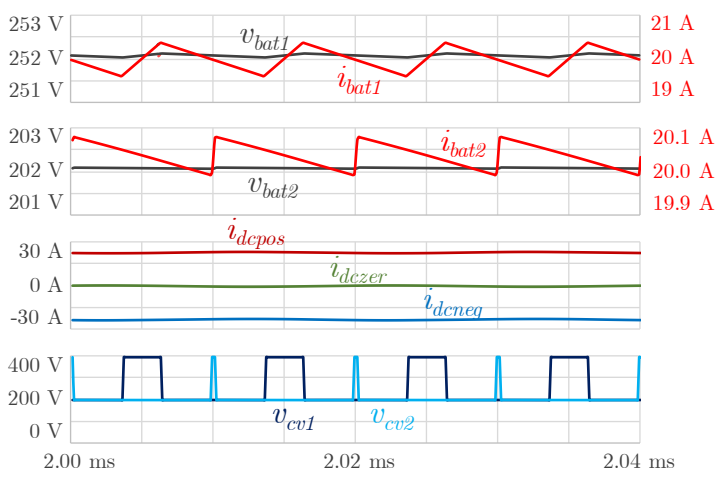

Fig. 3. Simulation results of the G2V operation mode when EV1 and EV2 are charging with a current of $20 \mathrm{~A}$.

Fig. 4 shows the operation of both EVs in G2V but with different values of current in order to simulate a case of unbalance. EV1 is charging with a current of $20 \mathrm{~A}$, while EV2 is charging with a current of $40 \mathrm{~A}$. The figure shows the battery voltages ( $v_{\text {bat }}$ and $\left.v_{\text {bat } 2}\right)$ and currents $\left(i_{\text {batl }}\right.$ and $\left.i_{\text {bat } 2}\right)$, the currents drawn from the dc power grid, namely in the positive rail $\left(i_{d c p o s}\right)$, neutral rail $\left(i_{d c z e r}\right)$ and negative rail $\left(i_{d c n e g}\right)$, and the voltages produced by the converters $\left(v_{c v 1}\right.$ and $\left.v_{c v 2}\right)$. In this case, the voltage $v_{\text {bat2 }}$ presents a value of $204 \mathrm{~V}$, showing the effect of the battery internal resistance when higher currents are applied. It can be seen that both battery currents present the expected average value, 
with EV1 presenting the same results as the previous case. Despite being a higher current, $i_{\text {bat } 2}$ still has a low ripple due to the same reason as previously mentioned, as it can be seen from voltages $v_{c v 1}$ and $v_{c v 2}$. Regarding the currents absorbed from the dc power grid, $i_{d c p o s}$ and $i_{d c n e g}$ are symmetrical but with a higher average value than previously (33.6 A), the first one being positive and the second being negative. Thus, the EV-BCS is able to consume balanced currents from the bipolar dc power grid even with unbalanced battery charging operation. Accordingly, the current $i_{d c z e r}$ presents a null average value.

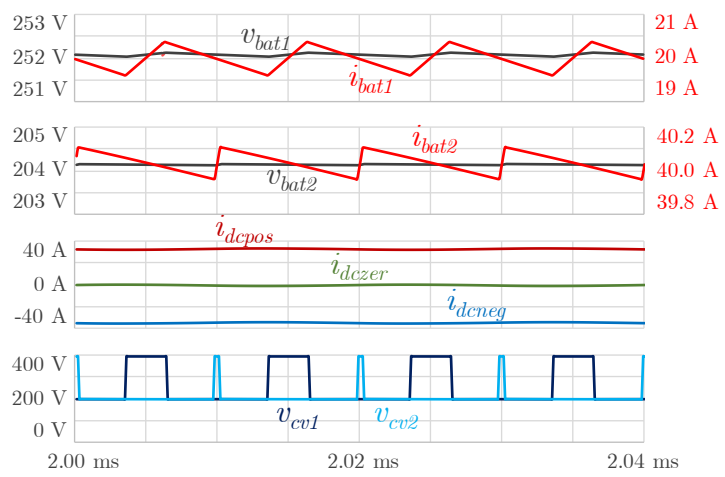

Fig. 4. Simulation results of the G2V operation mode when EV1 is charging with a current of $20 \mathrm{~A}$ and EV2 is charging with a current of $40 \mathrm{~A}$.

Fig. 5 shows the V2G operation mode for both EVs, discharging their batteries with the same value of current $(20 \mathrm{~A})$. This figure shows the battery voltages $\left(v_{\text {bat }}\right.$ and $\left.v_{\text {bat } 2}\right)$ and currents $\left(i_{b a t l}\right.$ and $\left.i_{b a t 2}\right)$, the currents drawn from the dc power grid, namely in the positive rail $\left(i_{d c p o s}\right)$, neutral rail $\left(i_{d c z e r}\right)$ and negative rail $\left(i_{d c n e g}\right)$, and the voltages produced by the converters $\left(v_{c v 1}\right.$ and $\left.v_{c v 2}\right)$. It can be seen that both battery currents are negative, meaning that the power flow is established from the batteries to the dc power grid, as expected in the V2G operation mode. Also, both battery currents present the same average value of $-20 \mathrm{~A}$, but $i_{\text {bat } 2}$ presents a much smaller ripple than $i_{\text {bat }}$, which is due to the same reason as aforementioned. In this case, the voltage produced by converter 2 $\left(v_{c v 2}\right)$ presents a very high duty-cycle between voltage levels $0 \mathrm{~V}$ and $200 \mathrm{~V}$ (in other words, presenting a duty-cycle slightly smaller than 50\%). This happens due to the internal resistance of the batteries, which decreases the battery voltage when current is being supplied by the battery, as it can be seen by the $v_{\text {bat }}$ value of $198 \mathrm{~V}$, which is lower than half the total dc power grid voltage. Regarding the dc power grid currents, it can be seen that $i_{d c p o s}$ and $i_{d c n e g}$ are symmetrical, but with $i_{d c p o s}$ being negative and $i_{d c n e g}$ being positive. This means that the dc power grid is receiving power instead of supplying it, as expected from the $\mathrm{V} 2 \mathrm{G}$ operation mode. The average value of these currents is $22.1 \mathrm{~A}$, with the current $i_{d c z e r}$ presenting a null average value. 


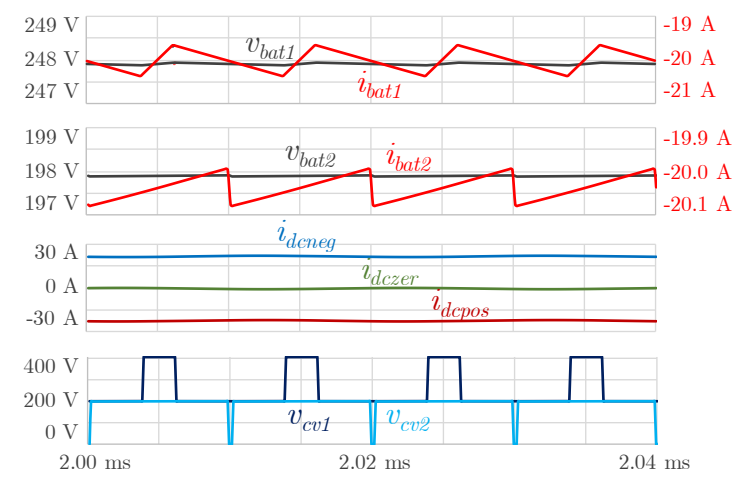

Fig. 5. Simulation results of the V2G operation mode when

EV1 and EV2 are discharging with a current of $20 \mathrm{~A}$.

Fig. 6 shows the operation of both EVs in V2G but with different values of current in order to simulate a case of unbalance. EV1 is discharging with a current of $20 \mathrm{~A}$, while EV2 is discharging with a current of $40 \mathrm{~A}$. The figure shows the battery voltages ( $v_{\text {bat }}$ and $\left.v_{\text {bat } 2}\right)$ and currents $\left(i_{\text {bat } 1}\right.$ and $\left.i_{\text {bat2 } 2}\right)$, the currents drawn from the dc power grid, namely in the positive rail $\left(i_{d c p o s}\right)$, neutral rail $\left(i_{d c z e r}\right)$ and negative rail $\left(i_{d c n e g}\right)$, and the voltages produced by the converters $\left(v_{c v 1}\right.$ and $\left.v_{c v 2}\right)$. Once again, both battery currents are negative, meaning that the power flow is established from the batteries to the dc power grid, as expected in the $\mathrm{V} 2 \mathrm{G}$ operation mode. It is noticeable that both battery currents present the expected average value, with EV1 presenting the same results as the previous scenario. In this case, the voltage $v_{\text {bat }}$ presents a value of $196 \mathrm{~V}$, showing the effect of the battery internal resistance when higher currents are drawn from the battery. Despite being a higher current, $i_{\text {bat } 2}$ still has a low ripple due to the same reason as previously mentioned, as it can be seen from voltages $v_{c v 1}$ and $v_{c v 2}$. Regarding the dc power grid currents, it is noticeable that $i_{d c p o s}$ is negative and $i_{d c n e g}$ is positive, as in the previous case, meaning that the dc power grid is receiving power instead of supplying it. Moreover, these currents are symmetrical, meaning that the EV-BCS is able to handle unbalances in the power injected by the EVs without unbalancing the dc power grid currents. The average value of these currents is $31.5 \mathrm{~A}$, with the current $i_{\text {dczer }}$ presenting a null average value. 


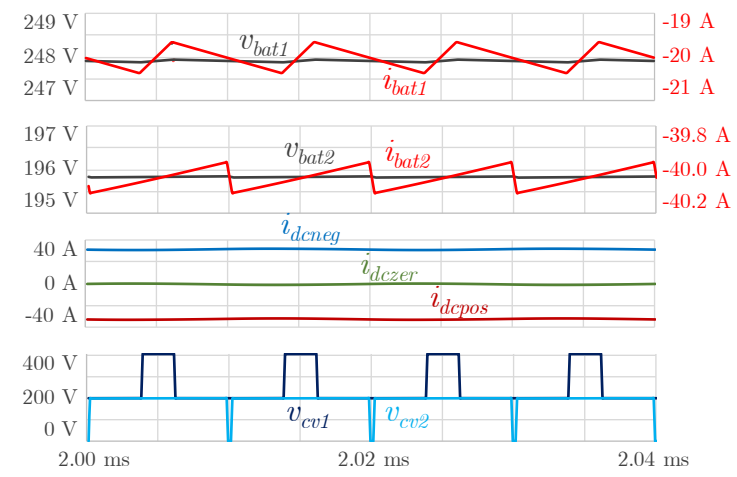

Fig. 6. Simulation results of the V2G operation mode when EV1 is discharging with a current of $20 \mathrm{~A}$ and EV2 is discharging with a current of $40 \mathrm{~A}$.

Fig. 7 shows the V2V operation mode, where EV1 provides power to EV2. EV2 is charging with a current of $20 \mathrm{~A}$, while EV1 provides the necessary current to perform the battery charging of EV2 without using additional power from the dc power grid. The figure shows the battery voltages $\left(v_{\text {bat }}\right.$ and $\left.v_{\text {bat } 2}\right)$ and currents $\left(i_{\text {batl }}\right.$ and $\left.i_{\text {bat } 2}\right)$, the currents drawn from the dc power grid, namely in the positive rail $\left(i_{\text {dcpos }}\right)$, neutral rail $\left(i_{d c z e r}\right)$ and negative rail $\left(i_{d c n e g}\right)$, and the voltages produced by the converters $\left(v_{c v l}\right.$ and $v_{c v 2}$ ). In this operation mode, $i_{b a t 1}$ is negative, similar to $\mathrm{V} 2 \mathrm{G}$, but $i_{\text {bat } 2}$ is positive, similar to $\mathrm{G} 2 \mathrm{~V}$. It can be seen that $i_{\text {bat } 2}$ has the expected average value of $20 \mathrm{~A}$, with $i_{\text {bat } 1}$ presenting an average value of approximately -16.3 A. In this case, the voltage $v_{b a t 2}$ has a value of $202 \mathrm{~V}$, making the produced voltage $v_{c v 2}$ alternate between voltage levels $200 \mathrm{~V}$ and $400 \mathrm{~V}$. Regarding the dc power grid currents, it can be seen that $i_{d c p o s}$ and $i_{d c n e g}$ are overlapped and with a practically null average value, meaning that the $\mathrm{dc}$ power grid is neither receiving nor providing significant power. The current $i_{d c z e r}$ presents a similar waveform, also with a null average value, as in the previous cases.

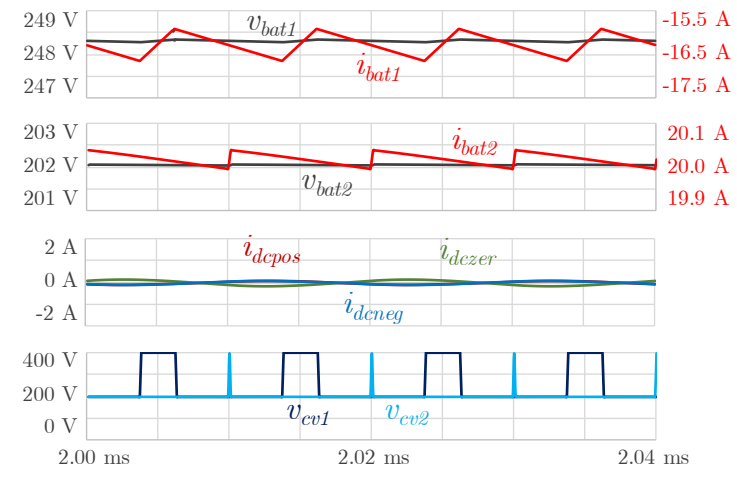

Fig. 7. Simulation results of the V2V operation mode when EV1 is discharging with a current of $16.3 \mathrm{~A}$ and EV2 is charging with a current of $20 \mathrm{~A}$. 
Fig. 8 shows the combination of V2V and G2V operation modes, where EV1 provides power to EV2, but the power provided by EV1 is not enough to perform the battery charging of EV2. EV1 is discharging with a current of $20 \mathrm{~A}$, while EV2 is charging with a current of $40 \mathrm{~A}$. The figure shows the battery voltages $\left(v_{b a t 1}\right.$ and $\left.v_{\text {bat }}\right)$ and currents $\left(i_{b a t l}\right.$ and $\left.i_{\text {bat } 2}\right)$, the currents drawn from the dc power grid, namely in the positive rail $\left(i_{d c p o s}\right)$, neutral rail $\left(i_{d c z e r}\right)$ and negative rail $\left(i_{d c n e g}\right)$, and the voltages produced by the converters $\left(v_{c v 1}\right.$ and $\left.v_{c v 2}\right)$. Once again, $i_{b a t 1}$ is negative, similar to $\mathrm{V} 2 \mathrm{G}$, but $i_{b a t 2}$ is positive, similar to G2V. Regarding the dc power grid currents, it can be seen that $i_{\text {dcpos }}$ is positive and $i_{\text {dcneg }}$ is negative, meaning that the dc power grid is providing power. However, the average value of these currents is only $8 \mathrm{~A}$, since the dc power grid only provides the power difference between the EV2 required power and the EV1 supplied power. Also, in this case, the currents $i_{d c p o s}$ and $i_{d c n e g}$ are symmetrical, with $i_{d c z e r}$ presenting a null average value.

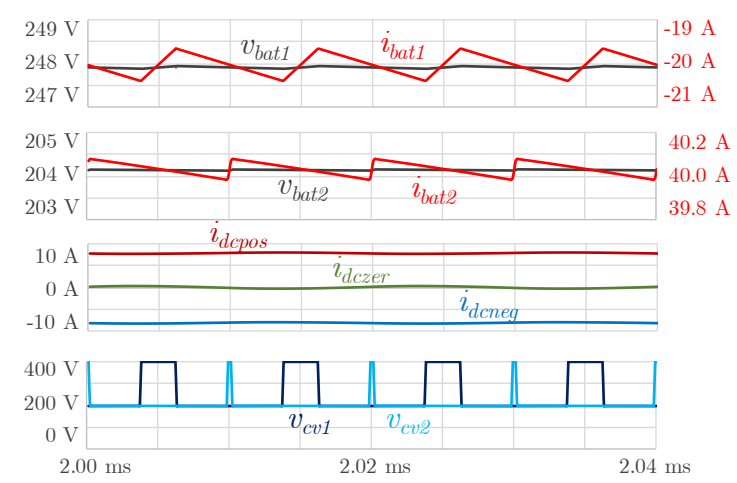

Fig. 8. Simulation results of the combination of $V 2 V$ and G2V operation modes when EV1 is discharging with a current of $20 \mathrm{~A}$ and EV2 is charging with a current of $40 \mathrm{~A}$.

Fig. 9 shows the combination of V2V and V2G operation modes, where EV1 provides power to EV2, but the power provided by EV1 is more than the power required to perform the battery charging of EV2. EV1 is discharging with a current of $40 \mathrm{~A}$, while EV2 is charging with a current of $20 \mathrm{~A}$. The figure shows the battery voltages ( $v_{\text {batl }}$ and $\left.v_{\text {bat } 2}\right)$ and currents $\left(i_{\text {batl }}\right.$ and $\left.i_{\text {bat } 2}\right)$, the currents drawn from the dc power grid, namely in the positive rail $\left(i_{d c p o s}\right)$, neutral rail $\left(i_{d c z e r}\right)$ and negative rail $\left(i_{d c n e g}\right)$, and the voltages produced by the converters ( $v_{c v 1}$ and $\left.v_{c v 2}\right)$. Once again, $i_{b a t l}$ is negative, similar to $\mathrm{V} 2 \mathrm{G}$, but $i_{\text {bat } 2}$ is positive, similar to G2V. Regarding the dc power grid currents, it can be seen that $i_{d c p o s}$ is negative and $i_{\text {dcneg }}$ is positive, contrarily to the previous case, meaning that the dc power grid is receiving power. The average value of these currents is only $14.4 \mathrm{~A}$, since the dc power grid only receives the power difference between the EV1 supplied power and the EV2 required power. As in the previous case, the currents $i_{d c p o s}$ and $i_{d c n e g}$ are symmetrical, with $i_{d c z e r}$ presenting a null average value. 


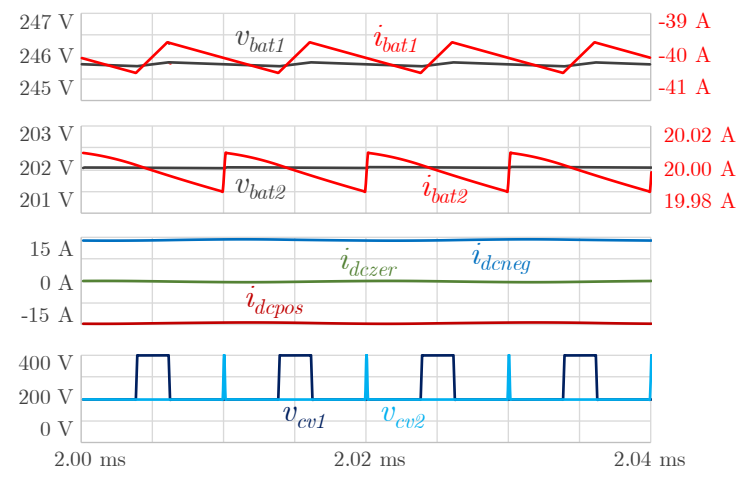

Fig. 9. Simulation results of the combination of $V 2 V$ and $V 2 G$ operation modes when EV1 is discharging with a current of $40 \mathrm{~A}$ and EV2 is charging with a current of $20 \mathrm{~A}$.

In order to provide an overview of the obtained simulation results, Table 2 shows the average values of the main variables for each case, i.e., $i_{b a t 1}, i_{\text {bat } 2}$ and $i_{d c p o s}$. The average values of $i_{d c n e g}$ and $i_{d c z e r}$ are not presented since the average value of $i_{d c n e g}$ is always symmetrical with respect to $i_{d c p o s}$, while the average value of $i_{d c z e r}$ is always null, as expected and previously explained.

Table 2. Average value of the currents obtained in the simulation results.

\begin{tabular}{cccc}
\hline \hline CASE & $I_{\text {bat }}$ & $I_{\text {bat } 2}$ & $I_{\text {dcpos }}$ \\
\hline \hline BALANCED G2V (FIG.3) & $20 \mathrm{~A}$ & $20 \mathrm{~A}$ & $23 \mathrm{~A}$ \\
\hline UNBALANCED G2V (FIG.4) & $20 \mathrm{~A}$ & $40 \mathrm{~A}$ & $33.6 \mathrm{~A}$ \\
\hline BALANCED V2G (FIG.5) & $-20 \mathrm{~A}$ & $-20 \mathrm{~A}$ & $-22.1 \mathrm{~A}$ \\
\hline UNBALANCED V2G (FIG.6) & $-20 \mathrm{~A}$ & $-40 \mathrm{~A}$ & $-31.5 \mathrm{~A}$ \\
\hline V2V (FIG.7) & $-16.3 \mathrm{~A}$ & $20 \mathrm{~A}$ & $0 \mathrm{~A}$ \\
\hline V2V + G2V (FIG.8) & $-20 \mathrm{~A}$ & $40 \mathrm{~A}$ & $8 \mathrm{~A}$ \\
\hline V2V + V2G (FIG.9) & $-40 \mathrm{~A}$ & $20 \mathrm{~A}$ & $-14.4 \mathrm{~A}$ \\
\hline
\end{tabular}

\section{Conclusions}

This paper presented a proposed electric vehicle battery charging station (EV-BCS) based on a bipolar dc power grid with vehicle-to-grid (V2G) and vehicle-to-vehicle $(\mathrm{V} 2 \mathrm{~V})$ operation modes capability, besides the traditional battery charging operation mode (grid-to-vehicle - G2V). The presented EV-BCS is modular and uses three-level bidirectional dc-dc converters. A case scenario with two converters, and thus two EVs, was considered, aiming to validate all the operation modes $(\mathrm{G} 2 \mathrm{~V}, \mathrm{~V} 2 \mathrm{G}$ and $\mathrm{V} 2 \mathrm{~V}$, as well as the combination of V2V with G2V, and V2V with V2G). Moreover, in all operation modes it was considered an unbalanced operation from the EVs side, in order to emulate a real operation scenario and validate the proper operation of the EV-BCS. The obtained results were based on computational simulations and verify the correct 
operation of the EV-BCS in all cases, with balanced and unbalanced current consumption from the EVs, but with balanced currents from the bipolar dc power grid side.

\section{Acknowledgments}

This work has been supported by FCT - Fundação para a Ciência e Tecnologia within the Project Scope: UID/CEC/00319/2019. This work has been supported by the FCT Project DAIPESEV PTDC/EEI-EEE/30382/2017, and by FCT Project newERA4GRIDs PTDC/EEI EEE/30283/2017. Mr. Tiago J. C. Sousa is supported by the doctoral scholarship SFRH/BD/134353/2017 granted by the Portuguese FCT agency.

\section{References}

1. C. C. Chan and Y. S. Wong, "Electric vehicles charge forward," IEEE Power and Energy Magazine, vol. 2, no. 6, pp. 24-33, Nov. 2004.

2. J. Milberg and A. Schlenker, "Plug into the Future," IEEE Power and Energy Magazine, vol. 9, no. 1, pp. 56-65, Jan. 2011.

3. J. Ansari, A. Gholami, A. Kazemi, and M. Jamei, "Environmental/economic dispatch incorporating renewable energy sources and plug-in vehicles," IET Generation, Transmission \& Distribution, vol. 8, no. 12, pp. 2183-2198, Dec. 2014.

4. K. Knezovic, S. Martinenas, P. B. Andersen, A. Zecchino, and M. Marinelli, "Enhancing the Role of Electric Vehicles in the Power Grid: Field Validation of Multiple Ancillary Services," IEEE Transactions on Transportation Electrification, vol. 3, no. 1, pp. 201-209, 2017.

5. H. N. T. Nguyen, C. Zhang, and J. Zhang, "Dynamic Demand Control of Electric Vehicles to Support Power Grid With High Penetration Level of Renewable Energy," IEEE Transactions on Transportation Electrification, vol. 2, no. 1, pp. 66-75, Mar. 2016.

6. W. Kempton and J. Tomić, "Vehicle-to-grid power implementation: From stabilizing the grid to supporting large-scale renewable energy," Journal of Power Sources, vol. 144, no. 1, pp. 280-294, 2005.

7. M. Kesler, M. C. Kisacikoglu, and L. M. Tolbert, "Vehicle-to-Grid Reactive Power Operation Using Plug-In Electric Vehicle Bidirectional Offboard Charger," IEEE Transactions on Industrial Electronics, vol. 61, no. 12, pp. 6778-6784, Dec. 2014.

8. V. Monteiro, J. G. Pinto, and J. L. Afonso, "Operation Modes for the Electric Vehicle in Smart Grids and Smart Homes: Present and Proposed Modes," IEEE Transactions on Vehicular Technology, vol. 65, no. 3, pp. 1007-1020, Mar. 2016.

9. Z. Moghaddam, I. Ahmad, D. Habibi, and Q. V. Phung, "Smart Charging Strategy for Electric Vehicle Charging Stations," IEEE Transactions on Transportation Electrification, vol. 4, no. 1, pp.76-88, Mar. 2018.

10. J. Yang, W. Wang, K. Ma, and B. Yang, "Optimal Dispatching Strategy for Shared Battery Station of Electric Vehicle by Divisional Battery Control," IEEE Access, vol. 7, pp.3822438235, 2019.

11. Y. Zhang, P. You, and L. Cai, "Optimal Charging Scheduling by Pricing for EV Charging Station With Dual Charging Modes," IEEE Transactions on Intelligent Transportation Systems, vol. 20, no. 9, pp.3386-3396, Sep. 2019. 
12. T. Morstyn, C. Crozier, M. Deakin, and M. D. McCulloch, "Conic Optimization for Electric Vehicle Station Smart Charging With Battery Voltage Constraints," IEEE Transactions on Transportation Electrification, vol. 6, no. 2, pp.478-487, Jun. 2020.

13. Q. Dai, T. Cai, S. Duan, and F. Zhao, "Stochastic modeling and forecasting of load demand for electric bus battery-swap station," IEEE Transactions on Power Delivery, vol. 29, no. 4, pp.1909-1917, 2014.

14. X. Tan, G. Qu, B. Sun, N. Li, and D. H. K. Tsang, "Optimal Scheduling of EV-BCS Serving Electric Vehicles Based on Battery Swapping," IEEE Transactions on Smart Grid, vol. 10, no. 2, pp.1372-1384, Mar. 2019.

15. X. Liu, T. Zhao, S. Yao, C. B. Soh, and P. Wang, "Distributed Operation Management of Battery Swapping-Charging Systems," IEEE Transactions on Smart Grid, vol. 10, no. 5, pp.5320-5333, Sep. 2019.

16. F. Ahmad, M. Saad Alam, I. Saad Alsaidan, and S. M. Shariff, "Battery swapping station for electric vehicles: opportunities and challenges," IET Smart Grid, vol. 3, no. 3, pp.280286, Jun. 2020.

17. M. Vasiladiotis and A. Rufer, "A Modular Multiport Power Electronic Transformer With Integrated Split Battery Energy Storage for Versatile Ultrafast EV Charging Stations," IEEE Transactions on Industrial Electronics, vol. 62, no. 5, pp.3213-3222, May 2015.

18. Q. Yan, B. Zhang, and M. Kezunovic, "Optimized Operational Cost Reduction for an EV Charging Station Integrated With Battery Energy Storage and PV Generation," IEEE Transactions on Smart Grid, vol. 10, no. 2, pp.2096-2106, Mar. 2019.

19. Y. Deng, Y. Zhang, and F. Luo, "Operational Planning of Centralized Charging Stations Using Second-Life Battery Energy Storage Systems," IEEE Transactions on Sustainable Energy, vol. 3029, no. c, pp.1-1, 2020.

20. B. T. Patterson, "DC, Come Home: DC Microgrids and the Birth of the 'Enernet," IEEE Power and Energy Magazine, vol. 10, no. 6, pp.60-69, 2012.

21. D. Kumar, F. Zare, and A. Ghosh, "DC Microgrid Technology: System Architectures, AC Grid Interfaces, Grounding Schemes, Power Quality, Communication Networks, Applications, and Standardizations Aspects," IEEE Access, vol. 5, pp.12230-12256, 2017.

22. L. Sun, F. Zhuo, F. Wang, and T. Zhu, "A Nonisolated Bidirectional Soft-Switching PowerUnit-Based DC-DC Converter With Unipolar and Bipolar Structure for DC Networks Interconnection," IEEE Transactions on Industry Applications, vol. 54, no. 3, pp.2677-2689, May 2018.

23. L. Guo, G. Yao, C. Huang, and L. Zhou, "Bipolar output direct-coupled DC-DC converter applied to DC grids," The Journal of Engineering, vol. 2019, no. 16, pp.1474-1479, Mar. 2019.

24. C. Perera, J. Salmon, and G. J. Kish, "Multiport Converter with Independent Control of AC and DC Power Flows for Bipolar DC Distribution," IEEE Transactions on Power Electronics, vol. 8993, no. c, pp.1-1, 2020.

25. S. Rivera, B. Wu, S. Kouro, V. Yaramasu, and J. Wang, "Electric Vehicle Charging Station Using a Neutral Point Clamped Converter With Bipolar DC Bus," IEEE Transactions on Industrial Electronics, vol. 62, no. 4, pp.1999-2009, Apr. 2015.

26. L. Tan, B. Wu, V. Yaramasu, S. Rivera, and X. Guo, "Effective Voltage Balance Control for Bipolar-DC-Bus-Fed EV Charging Station With Three-Level DC-DC Fast Charger," IEEE Transactions on Industrial Electronics, vol. 63, no. 7, pp.4031-4041, Jul. 2016.

27. L. Tan, B. Wu, S. Rivera, and V. Yaramasu, "Comprehensive DC Power Balance Management in High-Power Three-Level DC-DC Converter for Electric Vehicle Fast Charging," IEEE Transactions on Power Electronics, vol. 31, no. 1, pp.89-100, Jan. 2016. 
28. S. Rivera and B. Wu, "Electric Vehicle Charging Station With an Energy Storage Stage for Split-DC Bus Voltage Balancing," IEEE Transactions on Power Electronics, vol. 32, no. 3, pp.2376-2386, Mar. 2017.

29. S. Kim, H. Cha, and H.-G. Kim, "High-Efficiency Voltage Balancer Having DC-DC Converter Function for EV Charging Station," IEEE Journal of Emerging and Selected Topics in Power Electronics, vol. 6777, no. c, pp.1-1, 2019.

30. T. J. C. Sousa, V. Monteiro, J. C. A. Fernandes, C. Couto, A. A. N. Melendez, and J. L. Afonso, "New Perspectives for Vehicle-to-Vehicle (V2V) Power Transfer," in IECON 2018 - 44th Annual Conference of the IEEE Industrial Electronics Society, 2018, pp. 5183-5188.

31. S. Taghizadeh, P. Jamborsalamati, M. J. Hossain, and J. Lu, "Design and Implementation of an Advanced Vehicle-to-Vehicle (V2V) Power Transfer Operation Using Communications," in 2018 IEEE International Conference on Environment and Electrical Engineering and 2018 IEEE Industrial and Commercial Power Systems Europe (EEEIC / I\&CPS Europe), 2018, pp. 1-6.

32. X. Mou, R. Zhao, and D. T. Gladwin, "Vehicle to vehicle charging (V2V) bases on wireless power transfer technology," in IECON 2018 - 44th Annual Conference of the IEEE Industrial Electronics Society, 2018, pp. 4862-4867.

33. X. Mou, "Vehicle-to-Vehicle charging system fundamental and design comparison," in 2019 IEEE International Conference on Industrial Technology (ICIT), 2019, pp. 16281633.

34. M. Shen, F. Z. Peng, and L. M. Tolbert, "Multilevel DC-DC Power Conversion System With Multiple DC Sources," IEEE Transactions on Power Electronics, vol. 23, no. 1, pp.420-426, Jan. 2008.

35. M. Yilmaz and P. T. Krein, "Review of Battery Charger Topologies, Charging Power Levels, and Infrastructure for Plug-In Electric and Hybrid Vehicles," IEEE Transactions on Power Electronics, vol. 28, no. 5, pp. 2151-2169, May 2013.

36. V. Monteiro, T. J. C. Sousa, M. J. Sepúlveda, C. Couto, A. Lima, J. L. Afonso, "A Proposed Bidirectional Three Level dc-dc Power Converter for Applications in Smart Grids: An Experimental Validation", in 2019 IEEE SEST International Conference on Smart Energy Systems and Technologies, Porto, Portugal, Sept. 2019. 